\title{
The consequences of non-starch polysaccharide solubility and inclusion level on the health and performance of weaned pigs challenged with enterotoxigenic Escherichia coli
}

\author{
I. J. Wellock ${ }^{1 *}$, P. D. Fortomaris ${ }^{2}$, J. G. M. Houdijk ${ }^{1}$, J. Wiseman ${ }^{3}$ and I. Kyriazakis ${ }^{1,4}$ \\ ${ }^{1}$ Animal Nutrition and Health Department, Scottish Agricultural College, West Mains Road, Edinburgh EH9 3JG, UK \\ ${ }^{2}$ Department of Animal Production, School of Veterinary Medicine, Aristotle University of Thessaloniki, 54124 Thessaloniki, \\ Greece \\ ${ }^{3}$ Division of Agricultural and Environmental Sciences, School of Biosciences, University of Nottingham, Sutton Bonington Campus, \\ Loughborough LE12 5RD, UK \\ ${ }^{4}$ Faculty of Veterinary Medicine, University of Thessaly, Trikalon 224, GR-43100 Karditsa, Greece \\ (Received 21 February 2007 - Revised 20 June 2007 - Accepted 25 July 2007)
}

The inclusion of insoluble NSP (iNSP) in weaner pig diets has been reported to decrease post-weaning colibacillosis (PWC). Conversely, soluble NSP (sNSP) have been shown to exacerbate PWC. The present study investigated the effect of NSP solubility and inclusion level on the health and performance of newly weaned pigs challenged with enterotoxigenic Escherichia coli (ETEC), using NSP sources known not to affect digesta viscosity, in a $2 \times 2 \times 2$ factorial combination of NSP solubility (iNSP $v$. sNSP), inclusion level (low (L; $50 \mathrm{~g} / \mathrm{kg}) v$. high (H; $150 \mathrm{~g} / \mathrm{kg})$ ) and ETEC challenge (infected $v$. sham). Infection had no effect on pig health, but reduced performance to a larger extent in pigs on the L diets compared with those on the $\mathrm{H}$ diets. The inclusion of sNSP significantly decreased the occurrence of diarrhoea $(P<0.001)$ and improved gut health, as indicated by a lower caecal digesta $\mathrm{pH}(P=0.008)$ and increased $(P=0.002)$ Lactobacillus:coliform ratio, when compared with the iNSP diet on day 14 postweaning. There was no effect of NSP solubility on ETEC shedding, digesta viscosity or pig performance. Pigs on the $\mathrm{H}$ diets had fewer cases of diarrhoea and shed fewer ETEC than those on the L diets. Increasing NSP inclusion significantly increased colonic Lactobacillus:coliform ratio, volatile fatty acid concentration and caecal digesta viscosity, but decreased performance. These results suggest that sNSP per se are not detrimental to pig health and that increasing the concentration of NSP in weaner diets that do not increase digesta viscosity may have a beneficial effect on gut health and protect against PWC.

Inulin: Non-starch polysaccharides: Pigs: Post-weaning colibacillosis

There has been growing interest in the inclusion of dietary fibre, particularly NSP, in weaner pig diets because of its potential prebiotic properties, i.e. stimulation of the growth and/or activity of one or a limited number of beneficial bacteria species and the competitive exclusion of pathogens. Given that NSP constitute the major energy source for microbial fermentation ${ }^{1}$ and therefore act as a link between the piglet and its enteric microflora, there may be opportunities for manipulating the concentrations and types of dietary NSP offered to young pigs in order to improve gastrointestinal health and modulate the development of enteric disorders, such as post-weaning colibacillosis (PWC).

There is conflicting evidence as to whether NSP exert a beneficial or detrimental influence on pig health. The consumption of NSP from sources such as oats and barley hulls, all of which are rich in insoluble NSP (iNSP), have been linked to a reduction in the colonisation of the intestine by haemolytic Escherichia coli and the severity of $\mathrm{PWC}^{2,3}$. Conversely, diets containing NSP from sources which are rich in soluble NSP (sNSP), including pearl barley and guar gum, have been associated with an increased susceptibility to enteric disorders including PWC ${ }^{4,5}$, swine dysentery ${ }^{6}$ and porcine intestinal spirochaetosis ${ }^{7}$. As sNSP tend to be highly fermentable and viscous in nature ${ }^{8}$, this evidence raises the question of whether fermentability, viscosity or combinations of both are responsible for the observed detrimental effect of sNSP on pig health.

To investigate the potential detrimental effects of increased intestinal viscosity in the absence of NSP solubility effects, McDonald et al. $^{9}$ added carboxymethylcellulose, a synthetic viscous, non-fermentable sNSP, to rice-based weaner diets. Results showed that carboxymethylcellulose

Abbreviations: ADFI, average daily feed intake; ADG, average daily gain; cfu, colony-forming unit; BCR, branched-chain ratio; CS, cleanliness score; EBW\%, empty body weight percentage; ETEC, enterotoxigenic Escherichia coli; FS, faecal score; GIT, gastrointestinal tract; H, high inclusion of NSP; iNSP, insoluble NSP; L, low inclusion of NSP; PWC, post-weaning colibacillosis; sNSP, soluble NSP; VFA, volatile fatty acid.

* Corresponding author: Dr I. J. Wellock, fax +44 131 5353121, email ian.wellock@sac.ac.uk 
inclusion exacerbated PWC, suggesting that viscosity may be an important characteristic contributing to the predisposition to PWC, with increasing intestinal viscosity providing a favourable micro-environment for the proliferation of enterotoxigenic E. coli (ETEC). Any reported detrimental effects of feeding sNSP may therefore be due to the associated increase in digesta viscosity and not NSP solubility per se. Others reported no detrimental effects of increased carboxymethylcellulose inclusion, also in the absence of an experimental ETEC challenge ${ }^{10,11}$. The aim of the present experiment was to investigate the effects of NSP solubility and inclusion level on the gut health, gut development and pig performance of newly weaned pigs artificially challenged with ETEC in the absence of effects on digesta viscosity. It was hypothesised that, in the absence of effects on digesta viscosity, the inclusion of increased concentrations of both sNSP and iNSP would improve gut health and reduce ETEC proliferation. As sNSP tend to be more rapidly fermented than iNSP $^{1}$ it was expected that sNSP would act primarily in the proximal gastrointestinal tract (GIT) (for example, ileum and proximal colon), whereas iNSP would act more distally (for example, distal colon).

\section{Materials and methods}

\section{Animals and housing}

A total of sixty-four pigs (Large White $\times$ Landrace $\times$ White Duroc) of mixed sex, weaned at age 27 (SD 2.6) d and weighing 9.3 (SD 1.45) $\mathrm{kg}$ were used in the experiment. At weaning (day 0), pigs were removed from the sow, weighed, moved to a separate building and individually housed in pens $(2 \times 1 \mathrm{~m})$. The pens had a $0 \cdot 2 \mathrm{~m}$ deep transparent plastic partitioning along their length to enable visual contact between adjacent pens. Each pen was lightly bedded with sawdust and equipped with a single feeder and nipple drinker. No evidence of sawdust consumption by the pigs was observed during the experiment. Environmental temperature was maintained at $26^{\circ} \mathrm{C}$ for the first $3 \mathrm{~d}$ after weaning and then reduced by $2^{\circ} \mathrm{C}$ per week for the remainder of the experiment. Lights were on from 08.00 until 18.00 hours and fresh feed and water was available ad libitum throughout the experiment.

\section{Feeding and experimental design}

The experiment consisted of a $2 \times 2 \times 2$ factorial combination (eight per treatment) of NSP solubility (iNSP $v$. sNSP), NSP inclusion level (low (L) $v$. high $(\mathrm{H})$ ) and experimental ETEC challenge (infected $(+) v$. sham $(-)$ ). The increase in sNSP and iNSP was achieved by increasing inulin (Raftifeed ${ }^{\circledR}$ IPS; Orafti Active food ingredients, Tienen, Belgium) and highly purified cellulose (Solkafloc ${ }^{\circledR}$; International Fiber Corporation, New York, USA) respectively from $50 \mathrm{~g} / \mathrm{kg}$ in the $\mathrm{L}$ diets to $150 \mathrm{~g} / \mathrm{kg}$ in the $\mathrm{H}$ diets, at the expense of wheat starch. Inclusion levels for the $\mathrm{L}$ and $\mathrm{H}$ diets were chosen to give total NSP contents of about 100 and $200 \mathrm{~g} \mathrm{NSP} / \mathrm{kg}$ respectively. This compares to a total NSP content of $150 \mathrm{~g} / \mathrm{kg}$ in a typical weaner diet ${ }^{12-14}$. All diets contained similar amounts of cereal (i.e. background NSP) and were balanced for crude protein $(230 \mathrm{~g}$ crude protein $/ \mathrm{kg})$, dietary energy (16 MJ dietary energy/kg), amino acid composition and lactose content. Diets were formulated within the nutritional constraints of the experiment from readily available commercial ingredients using a best-cost formulation programme. The composition and chemical analyses of the experimental diets are shown in Table 1.

Piglets had access to a standard creep (16.0 MJ dietary energy $/ \mathrm{kg}$ and $235 \mathrm{~g}$ crude protein $/ \mathrm{kg}$ ) during the last $14 \mathrm{~d}$ of suckling to allow pigs to have experience of solid feed before weaning. Pigs were randomly assigned to the eight experimental treatments taking account of body weight and sex, with littermates equally divided across treatment groups. It was ensured that all uninfected pigs were housed in adjacent pens to minimise the risk of cross-infection from infected pigs. The Animal Experiments Committee of the Scottish Agricultural College approved the protocol used in the present study (ED AE 13/2005) for consistency with UK Home Office regulations.

\section{Experimental infection}

Pigs were infected with $10^{9}$ colony-forming units (cfu) of ETEC (E. coli O149) suspended in $10 \mathrm{ml}$ PBS on day 3 post-weaning to induce sub-clinical PWC following Wellock et al. ${ }^{15}$. These pathogens were derived from clinical cases of PWC (Veterinary Laboratories Agency, Addlestone, Surrey, UK) and had been characterised as having the required virulence factors to induce PWC (Adhesion factors K91, K88; F4). Pigs were not tested for susceptibility to these adhesion factors, but were from a herd where persistent post-weaning ETEC O149 shedding has been recorded. The infection was administered per os, using a stomach tube with an additional $10 \mathrm{ml}$ PBS for rinsing. Non-infected pigs were given $20 \mathrm{ml}$ of PBS as a sham infection. Pigs eating less than $50 \mathrm{~g} / \mathrm{d}$ before infection were not infected and removed from the experiment.

\section{Sampling collection and measurements}

Food intake and body weight. Pigs were fed at 09.00 hours each day with a known amount of feed and individual feed intake was recorded by weighing refusals the next day at the same time. Body weight was measured on days $0,3,6$ and 14 post-weaning.

Faecal score and sampling. Individual faecal score (FS) and cleanliness score (CS) were taken each morning throughout the experiment, and every $2 \mathrm{~h}$ post-infection for a period of $24 \mathrm{~h}$, using a subjective score on a four-point scale ranging from 1 to 4 , where $1=$ firm/clean and $4=$ watery/heavily contaminated (for further details, see Wellock et $a l^{16}$ ). Trained individuals with no prior knowledge of the treatment allocation recorded all scores. Fresh faecal samples were collected directly from the rectum on days 0, 3 (immediately before infection), 4, 5, 6, 9, 12 and 14 weaning to assess ETEC concentrations. This equates to days $-3,0,1,2,3$, 6, 9 and 11 post-infection.

Post mortem sampling procedures and measurements. Four pigs per treatment were euthanased on days 6 and 14 for measurement of gut health at two time points post-infection. Pigs were euthanased by intracardiac injection of 
Table 1. Diet composition and chemical analysis

\begin{tabular}{|c|c|c|c|c|}
\hline Diet... & $\mathrm{Hs}$ & $\mathrm{Hi}$ & Ls & $\mathrm{Li}$ \\
\hline \multicolumn{5}{|l|}{ Raw ingredients (g/kg) } \\
\hline Porridge oats & $150 \cdot 0$ & $150 \cdot 0$ & $150 \cdot 0$ & $150 \cdot 0$ \\
\hline Herring meal & $100 \cdot 0$ & $100 \cdot 0$ & $100 \cdot 0$ & $100 \cdot 0$ \\
\hline Dried skimmed milk powder & $125 \cdot 0$ & $125 \cdot 0$ & $125 \cdot 0$ & $125 \cdot 0$ \\
\hline Soycomil ${ }^{*}$ & $70 \cdot 0$ & $78 \cdot 0$ & $68 \cdot 0$ & 68.0 \\
\hline Full-fat soya & $70 \cdot 0$ & $66 \cdot 0$ & $70 \cdot 0$ & $70 \cdot 0$ \\
\hline Sucrose & $12 \cdot 5$ & $12 \cdot 5$ & $12 \cdot 5$ & $12 \cdot 5$ \\
\hline $50 \%$ Fat-filled whey & 62.5 & 112.5 & - & - \\
\hline Sweet whey & $37 \cdot 5$ & $12 \cdot 5$ & $68 \cdot 8$ & $68 \cdot 8$ \\
\hline Soya oil & $50 \cdot 0$ & $55 \cdot 0$ & $42 \cdot 0$ & $52 \cdot 0$ \\
\hline Raftifeed $®$ IPS† & $150 \cdot 0$ & - & $50 \cdot 0$ & - \\
\hline Solka-floc $\ddagger$ & - & $150 \cdot 0$ & - & $50 \cdot 0$ \\
\hline Wheat starch & - & - & $132 \cdot 0$ & $122 \cdot 0$ \\
\hline Dicalcium phosphate & $6 \cdot 9$ & $6 \cdot 8$ & $7 \cdot 4$ & $7 \cdot 4$ \\
\hline Limestone flour & $1 \cdot 80$ & 0.9 & 1.8 & $1 \cdot 6$ \\
\hline L-Lysine $\mathrm{HCl}$ & 0.34 & 0.32 & 0.40 & 0.42 \\
\hline DL-Methionine & 1.34 & 1.48 & $1 \cdot 30$ & $1 \cdot 30$ \\
\hline L-Threonine & 0.74 & 0.76 & 0.76 & 0.76 \\
\hline L-Tryptophan & 0.14 & 0.16 & 0.14 & 0.14 \\
\hline Sucram§ & 0.1 & 0.1 & 0.1 & 0.1 \\
\hline Premix\| & $10 \cdot 0$ & $10 \cdot 0$ & $10 \cdot 0$ & $10 \cdot 0$ \\
\hline Vanilla flavourq & 0.5 & 0.5 & 0.5 & 0.5 \\
\hline Total & $1000 \cdot 4$ & $1000 \cdot 5$ & $1000 \cdot 2$ & $1000 \cdot 0$ \\
\hline \multicolumn{5}{|c|}{ Chemical analysis ( $\mathrm{g} / \mathrm{kg}$ as fed or as specified) } \\
\hline Crude protein (per kg DM) & 228 & 237 & 235 & 240 \\
\hline Oil (diethyl ether extract) (per kg DM) & 105 & 133 & 82 & 87 \\
\hline Total starch plus sugars & 381.9 & $359 \cdot 7$ & $502 \cdot 2$ & $461 \cdot 2$ \\
\hline Insoluble NSP ${ }^{* \star}$ & 41.8 & $99 \cdot 7$ & 51.9 & 62.5 \\
\hline Soluble NSP plus fructans** & $127 \cdot 4$ & $77 \cdot 8$ & $54 \cdot 1$ & $32 \cdot 4$ \\
\hline Total NSP plus fructans ${ }^{\star \star}$ & $169 \cdot 2$ & 177.5 & $106 \cdot 0$ & 94.9 \\
\hline \multicolumn{5}{|c|}{ Calculated analysis ( $\mathrm{g} / \mathrm{kg}$ as fed or as specified) } \\
\hline Lactose & $100 \cdot 0$ & $100 \cdot 0$ & $100 \cdot 0$ & $100 \cdot 0$ \\
\hline $\mathrm{Ca}$ & 7.5 & 7.5 & 7.5 & 7.5 \\
\hline Digestible lysine & $14 \cdot 0$ & $14 \cdot 0$ & $14 \cdot 1$ & $14 \cdot 1$ \\
\hline Dietary energy (MJ/kg) & $16 \cdot 0$ & $16 \cdot 0$ & $16 \cdot 0$ & $16 \cdot 0$ \\
\hline
\end{tabular}

Hs, high soluble NSP; Hi, high insoluble NSP; Ls, low soluble NSP; Li, low insoluble NSP.

*ADM Feed Ingredients (Decatur, IL, USA).

† Orafti Active food ingredients (Tienen, Belgium).

¥International Fiber Corporation (New York, NY, USA).

$\S$ Pancosma SA, Geneva, Switzerland.

॥ Provided per kg of complete diet: $4.3 \mathrm{mg}$ vitamin $A, 56 \mu \mathrm{g}$ vitamin $\mathrm{D}_{3}, 250 \mathrm{mg}$ vitamin $\mathrm{E}, 5 \mathrm{mg}$ vitamin $\mathrm{K}_{3}, 4.2 \mathrm{mg}$ vitamin $\mathrm{B}_{1}, 5.7 \mathrm{mg}$ vitamin $\mathrm{B}_{2}, 5.2 \mathrm{mg}$ vitamin $\mathrm{B}_{6}, 42 \mu \mathrm{g}$ vita$\mathrm{min} \mathrm{B}_{12}, 42 \mathrm{mg}$ nicotinic acid, $21 \mathrm{mg}$ pantothenic acid, $1.1 \mathrm{mg}$ folic acid, $150 \mu \mathrm{g}$ biotin, $250 \mathrm{mg}$ choline chloride, $199 \mathrm{mg} \mathrm{Fe}\left(\right.$ as $\left.\mathrm{FeSO} . \mathrm{H}_{2} \mathrm{O}\right), 20 \mathrm{mg} \mathrm{Cu}\left(\right.$ as $\left.\mathrm{CuSO}_{4}\right), 65 \mathrm{mg} \mathrm{Mn}$ (as $\mathrm{MnO}$ ), $\left.0.5 \mathrm{mg} \mathrm{Co}\left(\mathrm{CoCO}_{3}\right), 100 \mathrm{mg} \mathrm{Zn} \mathrm{(as} \mathrm{ZnO}\right), 2.2 \mathrm{mg} \mathrm{I}\left(\right.$ as $\left.\mathrm{Ca}\left(\mathrm{IO}_{3}\right)_{2}\right)$ and $0.3 \mathrm{mg} \mathrm{Se}\left(\mathrm{as} \mathrm{NaSeO}_{4}\right)$.

ๆ Claremont Ingredients (Newcastle-under-Lyme, Staffs, UK).

${ }^{\star *}$ NSP analysis performed by Englyst Carbohydrates Ltd (Southampton, UK).

Euthatal $(0.7 \mathrm{mg} / \mathrm{ml}$; Merial Animal Health Ltd, Harlow, Essex, UK; $0.7 \mathrm{ml} / \mathrm{kg}$ ) and exsanguinated. The abdomen was opened from the sternum to the pubis, and the GIT removed. The GIT was divided into five sections (stomach, small intestine, caecum, proximal colon and distal colon). Each section was weighed full and empty to weights of organs and digesta contents. The $\mathrm{pH}$ of the digesta was measured by inserting the electrode of a portable $\mathrm{pH}$ meter (Testo 230; Testo Ltd, Alton, Hants, UK) into the collected sample after mixing. Digesta samples from the ileum, taken as the last $1 \mathrm{~m}$ of the small intestine, and proximal colon were assessed for Lactobacillus: coliform ratio and ETEC concentration. Further digesta samples from the ileum, proximal colon and caecum were immediately frozen in dry ice to inhibit microbial fermentation and stored at $-80^{\circ} \mathrm{C}$ until analysis for viscosity, solid:liquid ratio and volatile fatty acid (VFA) content.

\section{Microbiology}

Infective dose. A bead containing ETEC O149 was taken from storage at $-80^{\circ} \mathrm{C}$, reconstituted onto a sheep blood agar plate (E \& O Laboratories Ltd, Bonnybridge, Stirlingshire, UK) and incubated overnight at $37^{\circ} \mathrm{C}$. A number of representative colonies were removed from the plate, seeded into nutrient broth (Oxoid Ltd, Basingstoke, Hants, UK) and incubated at $37^{\circ} \mathrm{C}$ for $24 \mathrm{~h}$ whilst being shaken at $200 \mathrm{rpm}$. Bacteria were harvested by centrifugation, twice washed with PBS and re-suspended at a concentration of $1 \times 10^{8}$ $\mathrm{cfu} / \mathrm{ml}$. The number of cfu per $\mathrm{ml}$ was checked before being used for oral inoculation of the pigs using standard enumeration techniques (see below).

Detection and enumeration of enterotoxigenic Escherichia coli O149, Lactobacillus and coliforms. Each sample 
(approx $1 \mathrm{~g}$ ) was serially diluted to $10^{-9}$ in sterile PBS, and $100 \mu \mathrm{l}$ samples were plated on sheep blood agar (E \& O Laboratories Ltd, UK). The number of ETEC colonies was counted after $24 \mathrm{~h}$ incubation $\left(37^{\circ} \mathrm{C}\right)$ under aerobic conditions. Randomly picked colonies were identified and confirmed as the infective strain by slide agglutination with specific antiserum K91 and K88 (Mast Group Ltd, Bootle, Merseyside, UK). Lactobacilli and coliform counts were performed by standard enumeration techniques using De Man-RogosaSharpe and MacConkey agars (E \& O Laboratories Ltd) respectively. For further details, see Wellock et al. ${ }^{16}$.

\section{Volatile fatty acid analysis}

Digesta samples were thawed to $4^{\circ} \mathrm{C}$ and centrifuged at $4200 \mathrm{rpm}$ for $15 \mathrm{~min}$. From the resulting supernatant fraction, $1 \mathrm{ml}$ was mixed with $200 \mu \mathrm{l}$ of $25 \%$ metaphosphoric acid and incubated at room temperature for $30 \mathrm{~min}$ before a second centrifugation at $12000 \mathrm{rpm}$ for $10 \mathrm{~min}$. Chromatographic analysis was performed as described by Franklin et $a .^{17}$, using an Agilent gas chromatograph with a Varian CP7485 capillary column (Agilent Technologies, Inc., Santa Clara, CA, USA). A flame ionisation detector was used with an oven temperature of $140^{\circ} \mathrm{C}$, and a detector temperature of $250^{\circ} \mathrm{C}$, for determination of acetic, propionic, butyric, iso-butyric, valeric and iso-valeric acids. The branched-chain ratio (BCR) was calculated. This is the ratio of the VFA which are formed during the catabolism of branched-chain amino acids (valeric, iso-butyric and isovaleric acids) to those formed during carbohydrate fermentation (acetic, propionic and butyric) ${ }^{18}$.

\section{Measurement of digesta viscosity and solid:liquid ratio}

The rapid viscosity analyser (RVA) mixing viscosity of whole digesta samples from the ileum and caecum was determined at $37^{\circ} \mathrm{C}$ using the protocol of Lee et al. ${ }^{19}$. Briefly, after thawing at $4^{\circ} \mathrm{C}, 20 \mathrm{~g}$ digesta was mixed at $960 \mathrm{rpm}$ for $30 \mathrm{~s}$ followed by $160 \mathrm{rpm}$ for $5 \mathrm{~min}$. The RVA mixing viscosity was recorded every $1 \mathrm{~s}$ during mixing using two machines (RVA-Super-4 below $200 \mathrm{cP}$ and RVA-4 above $200 \mathrm{cP}$; Newport Scientific Pty Ltd). Data collected during the last $30 \mathrm{~s}$ was averaged. The solid:liquid ratio of whole digesta, indicative of the volume occupied by the solid particles from digesta and the regional liquid content, was determined by calculating the ratio between the weight of the wet pellet and that of the supernatant fraction after centrifugation.

\section{Statistical analysis}

The data were analysed as a $2 \times 2 \times 2$ factorial analysis of NSP type (sNSP $v$. iNSP), inclusion level $(\mathrm{H} v . \mathrm{L})$ and infection $(+v .-)$. The effects of the main factors, along with any interactions, were determined by restricted maximum likelihood methodology. Weaning weight was used as a covariate in all analyses. The individual pig was used as the experimental unit and litter as a random factor. The effect of slaughter day (time) on all $v$. recorded at slaughter was analysed by ANOVA with litter as a random factor. All statistical analyses were performed by Genstat 5 for Windows (release 4.2, service pack 2, 2001;
Lawes Agricultural Trust, Rothamsted, UK). Individual ETEC shedding was averaged over two time periods (days 4-6 and 4-14) and individual FS and CS were averaged over three time periods (days 3-6, 7-14 and 3-14) before analysis. Data from pigs euthanased on day 6 were not used in the analysis of ETEC over the 4 to $14 \mathrm{~d}$ period or for FS and CS over the 3 to $14 \mathrm{~d}$ period. Viscosity data, ETEC, Lactobacillus and coliform counts were $\log _{10}$ transformed before analysis and calculation of the Lactobacillus:coliform ratio.

\section{Results}

Faecal and cleanliness scores

None of the pigs suffered from clinical PWC or had to be removed from the experiment due to illness. However, one pig in treatment group $\mathrm{Li}+(\mathrm{L}$, iNSP, infection) was not infected due to persistent poor feed intake $(<50 \mathrm{~g} / \mathrm{d})$, and was removed from the experiment. Table 2 shows the mean FS and CS for the eight treatments. There were no significant effects of infection on FS or CS.

There was a significant effect of NSP solubility on FS and CS over the second week of the trial (days 7-14) and over the whole post-infection period (FS days 3-14; iNSP $1.90 v$. sNSP $1.49 ; P<0 \cdot 001)$. A significant NSP solubility $\times$ infection interaction existed for FS over the post-infection period (days 3-14), with infected pigs on the iNSP diets showing a much larger increase in FS than infected pigs on the sNSP diets when compared with their non-infected counterparts. Pigs fed the $\mathrm{H}$ diets tended to have lower FS than those on the L diets, although this was only significant in the $24 \mathrm{~h}$ period immediately post-infection (day 3), with an FS of 1.47 (SE 0.094) v. 1.74 (SE 0.312) for the $\mathrm{H}$ and $\mathrm{L}$ diets respectively $(P=0.049)$. There were no significant effects of NSP inclusion level on CS.

\section{Enterotoxigenic Escherichia coli excretion}

Neither the infection strain nor any other ETEC strain was detected in any of the pigs before the infectious challenge. However, ETEC colonies not belonging to the infective strain (K91 negative) were recovered from sixteen pigs, including eight non-infected pigs (two from each of the experimental treatment groups) on day 4 ( $n$ 9) or 5 ( $n$ 7) post-weaning for an average of $4 \mathrm{~d}$. This is thought to have been due to the proliferation of undetected ETEC already present in the GIT rather than contamination, as all pigs belonged to two of the eight litters used.

There was a significant effect of experimental infection on the number of ETEC excreted post-infection, with experimentally challenged pigs excreting more ETEC than their nonchallenged counterparts (days 4 to 14 ; sham $1.73 v$. infected $4.07 \log _{10} \mathrm{cfu} / \mathrm{g} ; P<0 \cdot 001$ ). All experimentally infected pigs excreted detectable numbers of ETEC immediately post-infection, shedding a mean of 7.3 (SE 0.30) $\log _{10} \mathrm{cfu}$ ETEC/g on day 4 (day 1 post-infection). This decreased to 1.3 (SE 0.92) $\log _{10} \mathrm{cfu} / \mathrm{g}$ by day 14 (day 11 post-infection), with only $25 \%$ of infected pigs still shedding detectable numbers of ETEC. NSP solubility did not affect ETEC shedding, with challenged pigs offered the iNSP and sNSP diets shedding 
Table 2. Effect of non-starch polysaccharide inclusion (high $(H) v$. low (L)), solubility (insoluble (i) $v$. soluble (s)) and experimental infection (infected $(+) v$. sham $(-))$ on mean faecal and cleanliness scores throughout the trial period $\dagger$ (Mean values and standard errors of the difference)

\begin{tabular}{|c|c|c|c|c|c|c|c|c|c|c|}
\hline & \multicolumn{8}{|c|}{ Treatment } & \multirow[b]{2}{*}{ SED $\ddagger$} & \multirow[b]{2}{*}{ Response } \\
\hline & Hs- & $\mathrm{Hi}-$ & Ls- & $\mathrm{Li}-$ & $\mathrm{Hs}+$ & $\mathrm{Hi}+$ & Ls + & $\mathrm{Li}+$ & & \\
\hline \multicolumn{11}{|l|}{ Faecal score } \\
\hline Day 3 & $1 \cdot 28$ & 1.49 & $2 \cdot 12$ & 1.49 & 1.40 & 1.70 & 1.60 & 1.74 & 0.296 & $I^{*}$ \\
\hline Days 3-6 & 1.54 & 2.08 & 1.78 & 1.92 & $2 \cdot 15$ & $2 \cdot 15$ & 1.54 & $2 \cdot 10$ & 0.193 & $S \times 1 \times E^{\star}$ \\
\hline Days $7-14$ & 1.00 & 1.52 & 1.75 & 1.65 & 1.45 & $2 \cdot 20$ & $1 \cdot 20$ & $2 \cdot 14$ & 0.329 & $S^{\star \star}$ \\
\hline Days $3-14$ & 1.08 & 1.55 & 1.90 & 1.56 & 1.61 & $2 \cdot 10$ & 1.27 & $2 \cdot 31$ & 0.274 & $S^{\star * \star}, S \times E^{*}$ \\
\hline \multicolumn{11}{|c|}{ Cleanliness score } \\
\hline Day 3 & 1.00 & 1.25 & $1 \cdot 34$ & $1 \cdot 23$ & 1.06 & $1 \cdot 16$ & 1.08 & $1 \cdot 32$ & 0.138 & \\
\hline Days 3-6 & 1.00 & 1.33 & 1.33 & 1.23 & $1 \cdot 17$ & 1.25 & 1.04 & $1 \cdot 14$ & 0.169 & \\
\hline Days $7-14$ & 1.00 & 1.19 & 1.50 & 1.54 & 1.13 & 1.44 & 1.00 & 1.53 & 0.195 & $\mathrm{~S}^{\star \star \star}$ \\
\hline Days $3-14$ & 1.02 & 1.30 & 1.30 & 1.40 & $1 \cdot 18$ & 1.41 & 1.00 & 1.45 & 0.154 & $\mathrm{~S}^{\star \star \star}$ \\
\hline
\end{tabular}

S, solubility (i v. s); I, inclusion level (H v. L); E, experimental infection (infected $v$. non-infected).

${ }^{\star} P<0.05,{ }^{* *} P<0.01,{ }^{* \star *} P<0.001$.

†Faecal and cleanliness scores were measured on a scale of 1 to 4 and their methodology is described in the Methods section.

$\ddagger$ Standard error of the difference for the $\mathrm{S} \times \mathrm{I} \times \mathrm{E}$ interaction.

an average of $4.4(\mathrm{SE} 1 \cdot 0)$ and $3 \cdot 8$ (SE 0.86) $\log _{10} \mathrm{cfu} / \mathrm{g}$ respectively over the post-infection period $(P=0 \cdot 587)$ (see Fig. 1 (a)). There was no effect of NSP inclusion level on number of ETEC shed post-infection (Fig. 1 (b)), although challenged
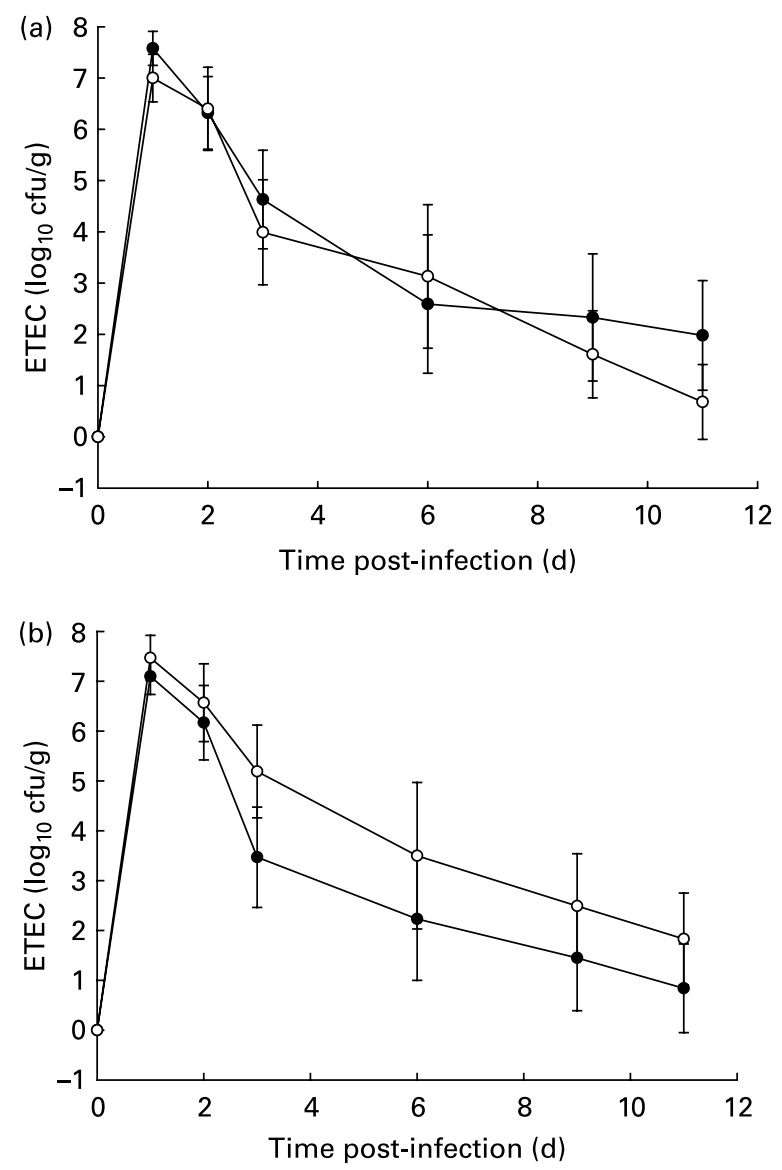

Fig. 1. The effect of (a) NSP solubility (soluble NSP (-O-) $v$. insoluble NSP $(-\bullet-)$ ) and (b) NSP inclusion level (low (-O-) $v$. high (-๑ -)) on faecal enterotoxigenic Escherichia coli (ETEC) shedding of challenged animals post-infection. Values are means, with their standard errors represented by vertical bars. cfu, Colony-forming units. pigs on the $\mathrm{H}$ diets tended to shed less ETEC than those on the $\mathrm{L}$ diets over the immediate post-infection period (days $4-6 ; \mathrm{H} 5 \cdot 3$ v. L $\left.6.2 \log _{10} \mathrm{cfu} / \mathrm{g} ; P=0.081\right)$. There was no effect of NSP solubility or inclusion level on the number of ETEC recovered from the ileum and proximal colon on day 6 or 14.

\section{Digesta viscosity and solid:liquid ratio, $p H$ and Lactobacillus:coliform ratio}

Tables 3 and 4 show the digesta viscosity, solid:liquid ratio, $\mathrm{pH}$ and Lactobacillus and coliform numbers on days 6 and 14 respectively. There was no effect of infection on digesta viscosity or solid:liquid ratio on day 6 or 14. There was a significant effect of NSP solubility on caecal solid:liquid ratio on days 6 and 14, with pigs on the sNSP diets having an increased ratio compared with those on the iNSP diets. NSP solubility had no effect on ileum or caecum digesta viscosity on either day 6 or 14. For example, on day 14 pigs on the iNSP and sNSP diets had mean ileal digesta viscosity of 1.6 (SE 0.24) v. 1.5 (SE 0.28) $\log \mathrm{cP}(P=0.732)$ respectively. Caecal digesta viscosity and solid:liquid ratio tended $(P<0.10)$ to be higher in pigs on the $\mathrm{H}$ diets than those on the L diets, although it was only significant for caecal solid:liquid ratio on day $6(\mathrm{H} 1.78 v$. L $0.62 ; P=0.022)$ and viscosity on day 14 ( $\mathrm{H} 2.7 v$. L $2.1 \log \mathrm{cP} ; P<0.001)$. There was no effect of inclusion level on ileum digesta viscosity or solid:liquid ratio.

There was no significant effect of infection on digesta $\mathrm{pH}$ on either day 6 or 14. Pigs fed sNSP had a lower caecal $\mathrm{pH}$ on day 14 than those fed iNSP (sNSP $5.3 v$. iNSP 5.5; $P=0.008)$. There were no other significant effects of NSP solubility on digesta $\mathrm{pH}$ on either day 6 or 14 . There was no significant effect of NSP inclusion level on digesta $\mathrm{pH}$ on day 6 . On day 14 , pigs offered the $\mathrm{H}$ diet had a significantly higher $\mathrm{pH}$ of ileum digesta than those offered the $\mathrm{L}$ diet (H 6.8 v. L 6.7; $P=0.008$ ).

The Lactobacillus:coliform ratio of the ileum $(P=0 \cdot 168)$ and proximal colon $(P=0.057)$ digesta increased with time, with overall mean values of 1.29 (SE 0.052) and 1.34 (SE 0.060) on day 6 increasing to 1.39 (SE 0.051) 
Table 3. Effect of non-starch polysaccharide inclusion (high (H) v. low (L)), solubility (insoluble (i) $v$. soluble (s)) and experimental infection (infected $(+) v$. sham $(-))$ on the $\mathrm{pH}$, Lactobacillus:coliform ratio, viscosity and solid:liquid ratio of whole digesta samples taken on day 6 post-weaning (Mean values and standard errors of the difference)

\begin{tabular}{|c|c|c|c|c|c|c|c|c|c|c|}
\hline & \multicolumn{8}{|c|}{ Treatment } & \multirow[b]{2}{*}{ SED† } & \multirow[b]{2}{*}{ Response } \\
\hline & $\mathrm{Hs}-$ & $\mathrm{Hi}-$ & Ls - & $\mathrm{Li}-$ & $\mathrm{Hs}+$ & $\mathrm{Hi}+$ & $\mathrm{Ls}+$ & $\mathrm{Li}+$ & & \\
\hline \multicolumn{11}{|l|}{$\mathrm{PH}$} \\
\hline Stomach & 3.00 & $3 \cdot 35$ & $3 \cdot 28$ & 3.73 & $2 \cdot 85$ & 3.85 & $3 \cdot 28$ & $2 \cdot 83$ & 0.849 & \\
\hline lleum & $7 \cdot 03$ & $7 \cdot 08$ & 6.55 & $7 \cdot 08$ & $7 \cdot 18$ & $7 \cdot 38$ & $7 \cdot 10$ & $6 \cdot 77$ & $0 \cdot 180$ & $S \times I \times E^{*}$ \\
\hline Proximal colon & $5 \cdot 83$ & $5 \cdot 65$ & 5.90 & $5 \cdot 83$ & $6 \cdot 08$ & $6 \cdot 05$ & $6 \cdot 33$ & $6 \cdot 20$ & 0.445 & \\
\hline Caecum & $5 \cdot 30$ & $6 \cdot 00$ & $6 \cdot 20$ & $5 \cdot 90$ & $6 \cdot 08$ & $6 \cdot 15$ & 5.93 & $5 \cdot 80$ & 0.368 & \\
\hline \multicolumn{11}{|c|}{ Lactobacilli $\left(\log _{10} \mathrm{cfu} / \mathrm{g}\right)$} \\
\hline lleum & $8 \cdot 11$ & $8 \cdot 10$ & $8 \cdot 86$ & $8 \cdot 60$ & $8 \cdot 11$ & $7 \cdot 62$ & 8.57 & $8 \cdot 35$ & 0.588 & \\
\hline Proximal colon & $8 \cdot 88$ & $8 \cdot 86$ & $9 \cdot 32$ & $9 \cdot 11$ & $9 \cdot 22$ & 8.75 & $9 \cdot 02$ & $8 \cdot 83$ & 0.419 & \\
\hline \multicolumn{11}{|c|}{ Coliforms $\left(\log _{10} \mathrm{cfu} / \mathrm{g}\right)$} \\
\hline Ileum & $5 \cdot 93$ & $6 \cdot 58$ & 6.65 & $7 \cdot 19$ & $6 \cdot 85$ & $6 \cdot 40$ & $7 \cdot 43$ & $6 \cdot 58$ & 0.866 & \\
\hline Proximal colon & $5 \cdot 21$ & $7 \cdot 34$ & $7 \cdot 75$ & $7 \cdot 46$ & $6 \cdot 44$ & $7 \cdot 34$ & $7 \cdot 39$ & $7 \cdot 56$ & 0.661 & $S^{\star}, I^{\star \star \star}, S \times I^{\star}$ \\
\hline \multicolumn{11}{|c|}{ Lactobacillus:coliform ratio } \\
\hline Ileum & 1.41 & 1.29 & $1 \cdot 41$ & $1 \cdot 21$ & $1 \cdot 21$ & $1 \cdot 27$ & $1 \cdot 18$ & $1 \cdot 34$ & 0.240 & \\
\hline Proximal colon & $1 \cdot 72$ & $1 \cdot 22$ & $1 \cdot 23$ & $1 \cdot 23$ & 1.59 & $1 \cdot 21$ & $1 \cdot 26$ & $1 \cdot 18$ & $0 \cdot 198$ & $S^{\star \star}, I^{\star \star}, S \times I^{\star}$ \\
\hline \multicolumn{11}{|l|}{ Viscosity (log cP) } \\
\hline Ileum & 0.89 & 0.83 & 0.60 & 0.65 & 1.00 & 1.54 & 1.03 & $2 \cdot 07$ & 0.88 & \\
\hline Caecum & $2 \cdot 71$ & $1 \cdot 28$ & 0.62 & 0.89 & 1.58 & $2 \cdot 22$ & 1.57 & $1 \cdot 27$ & 0.79 & \\
\hline \multicolumn{11}{|l|}{ Solid:liquid ratio } \\
\hline Ileum & $0 \cdot 21$ & 0.61 & 0.46 & 0.43 & 0.42 & 0.75 & 0.47 & 0.59 & 0.463 & \\
\hline Caecum & $3 \cdot 40$ & 0.77 & 0.43 & 0.47 & $1 \cdot 22$ & 0.89 & 0.54 & 0.56 & 0.878 & $I^{*}, S^{*}, S \times I^{*}$ \\
\hline
\end{tabular}

$\mathrm{S}$, solubility (i $v . \mathrm{s})$; I, inclusion level (H v. L); E, experimental infection (infected $v$. non-infected).

${ }^{\star} P<0.05,{ }^{\star \star} P<0.01,{ }^{\star \star \star} P<0.001$.

†Standard error of the difference for the $S \times I \times E$ interaction.

$\underset{\widetilde{J}}{\widetilde{C}}$ and 1.46 (SE 0.039) respectively on day 14 . This was due to a significant decrease in coliform numbers in both the ileum (day $6=6.71 v$. day $14=6.11 ; P=0.049$ ) and proximal colon (day $6=7.04 v$. day $14=6.28 ; P=0.008$ ). There was no significant effect of infection on the Lactobacillus: coliform ratio of the ileum and proximal colon digesta on either day 6 or 14. Pigs fed sNSP diets had an increased Lactobacillus:coliform ratio in the proximal colon digesta compared with those fed iNSP diets on both days 6 (sNSP $1.45 v$. iNSP $1.21 ; P=0.008$ ) and 14 (sNSP $1.57 v$.

Table 4. Effect of non-starch polysaccharide inclusion (high $(\mathrm{H}) v$. low (L)), solubility (insoluble (i) $v$. soluble (s)) and experimental infection (infected $(+) v$. sham $(-))$ on the $\mathrm{pH}$, Lactobacillus:coliform ratio, viscosity and solid:liquid ratio of whole digesta samples taken on day 14 post-weaning (Mean values and standard errors of the difference)

\begin{tabular}{|c|c|c|c|c|c|c|c|c|c|c|}
\hline & \multicolumn{8}{|c|}{ Treatment } & \multirow[b]{2}{*}{ SED† } & \multirow[b]{2}{*}{ Response } \\
\hline & $\mathrm{Hs}-$ & $\mathrm{Hi}-$ & Ls - & $\mathrm{Li}-$ & $\mathrm{Hs}+$ & $\mathrm{Hi}+$ & $\mathrm{Ls}+$ & $\mathrm{Li}+$ & & \\
\hline Stomach & $2 \cdot 15$ & $3 \cdot 15$ & $3 \cdot 63$ & $3 \cdot 10$ & $3 \cdot 25$ & $3 \cdot 10$ & $3 \cdot 20$ & $3 \cdot 85$ & 0.931 & \\
\hline Ileum & $6 \cdot 80$ & 6.98 & $6 \cdot 68$ & $6 \cdot 73$ & 6.73 & $6 \cdot 78$ & 6.88 & $6 \cdot 33$ & $0 \cdot 182$ & $I^{* *}$ \\
\hline Proximal colon & 5.45 & $5 \cdot 68$ & $5 \cdot 75$ & 5.93 & 5.45 & $5 \cdot 60$ & $5 \cdot 80$ & $5 \cdot 73$ & 0.275 & \\
\hline Caecum & $5 \cdot 28$ & $6 \cdot 45$ & $5 \cdot 28$ & 5.50 & $5 \cdot 10$ & $5 \cdot 50$ & 5.45 & $5 \cdot 73$ & 0.229 & $S^{* *}$ \\
\hline \multicolumn{11}{|c|}{ Lactobacilli $\left(\log _{10} \mathrm{cfu} / \mathrm{g}\right)$} \\
\hline lleum & $7 \cdot 98$ & $7 \cdot 95$ & $8 \cdot 42$ & 8.07 & 8.06 & $8 \cdot 21$ & $8 \cdot 31$ & $8 \cdot 77$ & 0.539 & \\
\hline Proximal colon & 9.53 & $9 \cdot 22$ & $9 \cdot 07$ & 8.90 & $8 \cdot 68$ & $8 \cdot 33$ & $9 \cdot 14$ & $9 \cdot 34$ & 0.353 & $L \times E^{\star \star}$ \\
\hline \multicolumn{11}{|c|}{ Coliforms $\left(\log _{10} \mathrm{cfu} / \mathrm{g}\right)$} \\
\hline lleum & $6 \cdot 69$ & $6 \cdot 28$ & $5 \cdot 89$ & $6 \cdot 27$ & $5 \cdot 38$ & $6 \cdot 28$ & 6.07 & $6 \cdot 00$ & 0.743 & \\
\hline Proximal colon & $5 \cdot 96$ & $6 \cdot 42$ & $6 \cdot 26$ & $6 \cdot 71$ & $5 \cdot 15$ & $6 \cdot 62$ & $6 \cdot 27$ & $6 \cdot 83$ & 0.470 & $\mathrm{~S}^{\star \star \star}$ \\
\hline \multicolumn{11}{|c|}{ Lactobacillus:coliform ratio } \\
\hline Ileum & $1 \cdot 24$ & $1 \cdot 27$ & 1.53 & $1 \cdot 31$ & 1.52 & $1 \cdot 34$ & $1 \cdot 39$ & 1.51 & $0 \cdot 213$ & \\
\hline Proximal colon & 1.62 & 1.44 & 1.46 & $1 \cdot 32$ & $1 \cdot 70$ & 1.27 & 1.48 & $1 \cdot 38$ & $0 \cdot 140$ & $S^{\star *}$ \\
\hline lleum & $1 \cdot 39$ & $2 \cdot 35$ & $2 \cdot 37$ & 0.96 & 0.99 & 1.55 & $1 \cdot 29$ & $1 \cdot 38$ & 0.68 & $S \times 1^{*}$ \\
\hline Caecum & $2 \cdot 86$ & $2 \cdot 82$ & 2.48 & $1 \cdot 39$ & $2 \cdot 84$ & $2 \cdot 27$ & $2 \cdot 13$ & $1 \cdot 22$ & 0.34 & $I^{\star \star \star}$ \\
\hline \multicolumn{11}{|l|}{ Solid:liquid ratio } \\
\hline Ileum & 0.67 & 1.49 & 1.02 & 0.62 & 0.45 & 0.94 & 0.55 & 0.71 & 0.457 & \\
\hline Caecum & $2 \cdot 84$ & $1 \cdot 75$ & 3.08 & 0.58 & $6 \cdot 00$ & 1.47 & $1 \cdot 55$ & 0.74 & $1 \cdot 804$ & $S^{*}$ \\
\hline
\end{tabular}

$\mathrm{S}$, solubility (i v. s); I, inclusion level (H v. L); E, experimental infection (infected $v$. non-infected).

${ }^{\star} P<0.05,{ }^{\star \star} P<0.01,{ }^{\star \star *} P<0.001$.

tStandard error of the difference for the $S \times I \times E$ interaction. 
iNSP $1.37 ; P=0.002$ ), mainly due to a significant decrease in coliform numbers. Pigs fed the $\mathrm{H}$ diet had numerically higher Lactobacillus:coliform ratios than those fed the $\mathrm{L}$ diet, although this was only significant in the proximal colon on day $6(\mathrm{~L} 1.23 v$. H $1.44 ; P=0.007)$. There was a significant NSP solubility $\times$ NSP level interaction on day 6 for the Lactobacillus:coliform ratio in proximal colon digesta, due to a larger decrease in the number of coliforms in the digesta of pigs fed sNSP compared with iNSP as inclusion level increased.

\section{Volatile fatty acid molar proportions}

The effect of infection, NSP solubility and inclusion level on digesta VFA molar proportions are shown in Table 5. Values for proximal colon digesta on day 6 are not shown because of the large number of missing vales due to insufficient supernatant fraction allowing VFA measurement. On day 6, pigs offered the sNSP diets had a significantly $(P<0.01)$ higher proportion of acetic, butyric and valeric acid in caecum digesta than those offered iNSP-containing diets. On day 14 VFA molar proportions were significantly higher for the sNSP-fed pigs for acetic, propionic, butyric and valeric acids in caecum $(P<0.001)$ and acetic, butyric, valeric and iso-butyric acids in the proximal colon $(P<0.05)$ digesta compared with those fed iNSP diets. On day 14, pigs on the sNSP diets had a higher BCR in the caecum (sNSP $0.07 v$. iNSP $0.04 ; P=0.020$ ) and proximal colon
(sNSP $0.15 v$. iNSP $0.05 ; P=0.024$ ) than those on the iNSP diets. Pigs fed the $\mathrm{H}$ diets tended to have increased VFA molar proportions, although this was only significant for valeric acid in the caecum digesta and butyric, valeric and iso-butyric acids in the proximal colon digesta on day 14. Pigs on the $\mathrm{H}$ diets had a higher $\mathrm{BCR}$ in caecum digesta on day 14 compared with those on the L diets ( $0.07 v$. L $0.04 ; P=0.007)$. There was a significant NSP solubility $\times$ NSP inclusion interaction on the BCR in caecum digesta on day 14, with increasing NSP concentration leading to a larger increase in BCR in pigs fed sNSP diets compared with those on iNSP diets.

\section{Gut development}

The empty organ weights from days 6 and 14 are shown in Table 6. Infection had a significant effect on colon weight on day 6 , with infected pigs having heavier colons, both in absolute terms and as a percentage GIT (\%GIT) than non-infected pigs (sham $20 \cdot 1 \mathrm{v}$. infected $22.2 \%$ GIT; $P=0.038$ ). The difference remained on day 14 but was no longer significant.

There was a significant effect of NSP solubility on caecum weight, with pigs fed the sNSP diet having heavier caecums than those on the iNSP diets on both days 6 (sNSP $24 v$. iNSP $21 \mathrm{~g} ; P=0.010$ ) and 14 (sNSP $42 v$. iNSP $32 \mathrm{~g}$; $P<0.001)$. Pigs on the $\mathrm{H}$ diets tended to have heavier empty organ weights than those on the L diets, with significantly heavier caecums and colons on day 6 . When calculated as \%GIT,

Table 5. Effect of non-starch polysaccharide inclusion (high $(\mathrm{H}) v$. low (L)), solubility (insoluble (i) $v$. soluble (s)) and experimental infection (infected $(+) \mathrm{v}$. sham $(-)$ ) on concentrations of volatile fatty acids (molar proportions) in intestinal digesta on days 6 and 14 post-weaning (Mean values and standard errors of the difference)

\begin{tabular}{|c|c|c|c|c|c|c|c|c|c|c|}
\hline & \multicolumn{8}{|c|}{ Treatment } & \multirow[b]{2}{*}{ SED† } & \multirow[b]{2}{*}{ Response } \\
\hline & $\mathrm{Hs}-$ & $\mathrm{Hi}-$ & Ls - & $\mathrm{Li}-$ & $\mathrm{Hs}+$ & $\mathrm{Hi}+$ & $\mathrm{Ls}+$ & $\mathrm{Li}+$ & & \\
\hline \multicolumn{11}{|l|}{ Day 6 caecum } \\
\hline Acetic acid & $50 \cdot 8$ & 66.9 & $60 \cdot 4$ & $66 \cdot 6$ & $65 \cdot 3$ & $54 \cdot 8$ & $62 \cdot 2$ & $65 \cdot 1$ & $7 \cdot 17$ & $\mathrm{~S}^{* *}$ \\
\hline Propionic acid & $27 \cdot 4$ & $16 \cdot 1$ & $25 \cdot 1$ & $19 \cdot 8$ & $20 \cdot 3$ & 23.5 & $25 \cdot 0$ & $23 \cdot 2$ & $3 \cdot 29$ & $S^{\star \star \star}$ \\
\hline Butyric acid & $13 \cdot 1$ & $5 \cdot 3$ & $10 \cdot 1$ & $6 \cdot 3$ & 8.0 & $12 \cdot 8$ & $7 \cdot 0$ & 8.5 & $3 \cdot 36$ & $S^{\star \star}$ \\
\hline Valeric acid & 6.5 & $4 \cdot 4$ & 1.9 & $2 \cdot 6$ & $1 \cdot 2$ & $6 \cdot 2$ & $1 \cdot 7$ & 1.0 & $2 \cdot 81$ & \\
\hline Iso-butyric acid & 0.4 & 0.2 & 0.5 & 0.7 & 0.4 & 0.5 & 1.0 & 0.6 & 0.36 & \\
\hline Iso-valeric acid & $1 \cdot 8$ & $7 \cdot 1$ & 1.9 & $4 \cdot 0$ & 4.9 & $2 \cdot 2$ & $3 \cdot 1$ & 1.6 & 3.89 & \\
\hline BCR & 0.10 & 0.18 & 0.05 & 0.08 & 0.07 & $0 \cdot 10$ & 0.06 & 0.03 & 0.09 & \\
\hline \multicolumn{11}{|c|}{ Day 14 proximal colon } \\
\hline Acetic acid & $39 \cdot 7$ & $61 \cdot 3$ & $57 \cdot 7$ & $65 \cdot 4$ & $67 \cdot 4$ & $47 \cdot 5$ & $65 \cdot 7$ & $62 \cdot 6$ & $7 \cdot 26$ & $S^{* * *}, S \times I^{*}$ \\
\hline Propionic acid & $24 \cdot 2$ & $22 \cdot 6$ & $16 \cdot 8$ & $20 \cdot 6$ & $17 \cdot 7$ & $30 \cdot 1$ & $20 \cdot 3$ & $23 \cdot 6$ & $7 \cdot 14$ & \\
\hline Butyric acid & $22 \cdot 4$ & $10 \cdot 4$ & $10 \cdot 4$ & $8 \cdot 7$ & $11 \cdot 0$ & $13 \cdot 4$ & $9 \cdot 8$ & $10 \cdot 0$ & $3 \cdot 35$ & $S^{*}, I^{*}, S \times I^{*}$ \\
\hline Valeric acid & $11 \cdot 8$ & $2 \cdot 0$ & 3.5 & $1 \cdot 8$ & $1 \cdot 7$ & $8 \cdot 4$ & 1.9 & $1 \cdot 8$ & 1.66 & $S^{* \star *}, I^{* \star *}, S \times I^{* \star *}$ \\
\hline Iso-butyric acid & 0.1 & 0.5 & 0.4 & 0.9 & 0.4 & $0 \cdot 2$ & 0.9 & 0.7 & 0.24 & $S^{\star}, I^{\star \star}$ \\
\hline Iso-valeric acid & $1 \cdot 7$ & $3 \cdot 2$ & $11 \cdot 2$ & $2 \cdot 5$ & $1 \cdot 8$ & 0.4 & 1.4 & 1.4 & $5 \cdot 47$ & \\
\hline BCR & 0.16 & 0.06 & 0.21 & 0.06 & 0.04 & $0 \cdot 10$ & 0.04 & 0.04 & 0.090 & $S^{*}$ \\
\hline \multicolumn{11}{|l|}{ Day 14 caecum } \\
\hline Acetic acid & $52 \cdot 4$ & 66.9 & $57 \cdot 4$ & $68 \cdot 0$ & $69 \cdot 0$ & $50 \cdot 6$ & 61.9 & $63 \cdot 7$ & 3.99 & $S^{\star \star \star}, S \times I^{\star \star}$ \\
\hline Propionic acid & $25 \cdot 8$ & $20 \cdot 4$ & $27 \cdot 7$ & $19 \cdot 8$ & $20 \cdot 4$ & $29 \cdot 7$ & 24.5 & $24 \cdot 3$ & $2 \cdot 60$ & $S^{\star \star \star}$ \\
\hline Butyric acid & $13 \cdot 1$ & 8.9 & $12 \cdot 1$ & $7 \cdot 7$ & $6 \cdot 6$ & 9.9 & $10 \cdot 4$ & $7 \cdot 7$ & 1.50 & $S^{\star \star \star}, E^{\star \star}$ \\
\hline Valeric acid & $6 \cdot 4$ & 1.9 & $2 \cdot 4$ & 1.5 & 1.5 & 6.4 & 1.9 & $1 \cdot 2$ & $1 \cdot 19$ & $S^{\star \star \star}, I^{\star \star \star}, S \times I^{\star \star \star}$ \\
\hline Iso-butyric acid & 0.4 & 0.4 & 0.1 & 0.6 & 0.2 & 0.2 & 0.4 & 0.3 & 0.45 & $S \times E^{*}$ \\
\hline Iso-valeric acid & 1.9 & 1.5 & 0.3 & $2 \cdot 5$ & $2 \cdot 3$ & $3 \cdot 2$ & 0.9 & $2 \cdot 8$ & 1.388 & \\
\hline BCR & 0.10 & 0.04 & 0.03 & 0.05 & 0.04 & 0.11 & 0.03 & 0.05 & 0.023 & $S^{*}, I^{\star \star \star}, S \times I^{\star \star \star}$ \\
\hline
\end{tabular}

$\mathrm{S}$, solubility (i v. s); BCR, branched-chain ratio (valeric, iso-butyric and iso-valeric acids:acetic, propionic and butyric acids ratio); I, inclusion level (H v. L); E, experimental infection (infected $v$. non-infected).

${ }^{\star} P<0.05,{ }^{\star \star} P<0.01,{ }^{\star \star \star} P<0.001$.

†Standard error of the difference for the $S \times I \times E$ interaction. 
Table 6. Effect of non-starch polysaccharide inclusion (high (H) v. low (L)), solubility (insoluble (i) $v$. soluble (s)) and experimental infection (infected $(+) v$. sham $(-)$ ) on empty organ weight on days 6 and 14 post-weaning

(Mean values and standard errors of the difference)

\begin{tabular}{|c|c|c|c|c|c|c|c|c|c|c|}
\hline & \multicolumn{8}{|c|}{ Treatment } & \multirow[b]{2}{*}{ SED† } & \multirow[b]{2}{*}{ Response } \\
\hline & $\mathrm{Hs}-$ & $\mathrm{Hi}-$ & Ls - & $\mathrm{Li}-$ & $\mathrm{Hs}+$ & $\mathrm{Hi}+$ & $\mathrm{Ls}+$ & $\mathrm{Li}+$ & & \\
\hline \multicolumn{11}{|c|}{ Day 6 empty organ weight (g) } \\
\hline Stomach & 73 & 68 & 61 & 68 & 81 & 72 & 66 & 67 & $5 \cdot 5$ & \\
\hline Small intestine & 514 & 459 & 455 & 408 & 497 & 474 & 468 & 538 & $52 \cdot 4$ & \\
\hline Caecum & 30 & 19 & 18 & 20 & 26 & 26 & 21 & 18 & $3 \cdot 0$ & $S^{*}, I^{\star *}, S \times I \times E^{\star *}$ \\
\hline Colon & 158 & 156 & 124 & 116 & 185 & 180 & 143 & 170 & 21.9 & $\mathrm{I}^{\star}, \mathrm{E}^{\star \star}$ \\
\hline \multicolumn{11}{|c|}{ Day 14 empty organ weight (g) } \\
\hline Stomach & 99 & 98 & 109 & 101 & 94 & 88 & 102 & 86 & $9 \cdot 2$ & \\
\hline Small intestine & 703 & 793 & 937 & 842 & 661 & 596 & 835 & 724 & $116 \cdot 8$ & \\
\hline Caecum & 41 & 34 & 47 & 31 & 45 & 33 & 37 & 30 & 5.5 & $S^{\star \star \star}, I \times E^{*}$ \\
\hline Colon & 245 & 237 & 262 & 238 & 261 & 231 & 214 & 188 & $25 \cdot 7$ & $I \times E^{*}$ \\
\hline
\end{tabular}

$\mathrm{S}$, solubility (i $v . \mathrm{S}$ ); I, inclusion level (H v. L); E, experimental infection (infected $v$. non-infected).

${ }^{\star} P<0.05,{ }^{*} P<0.01,{ }^{* \star *} P<0.001$.

†Standard error of the difference for the $S \times I \times E$ interaction.

pigs on the $\mathrm{H}$ diet had heavier caecums $(\mathrm{H} 3.4$ v. L $2.9 \%$; $P=0.029)$ and colons (H $22.4 v . \mathrm{L} 19.9 \% ; P=0.041)$ and lighter small intestines $(\mathrm{H} 64.3 v$. L $67.6 \% ; P=0.013)$ than pigs on the $\mathrm{L}$ diet. These differences remained on day 14 but were only significant for the colon. There were no significant NSP solubility $\times$ NSP inclusion level interactions on gut development.

\section{Pig performance}

There was no significant effect of infection on average daily gain (ADG), average daily feed intake (ADFI) or feed conversion ratio over the experimental period (Table 7). There was, however, a significant infection $\times$ inclusion level interaction on ADG and ADFI immediately post-infection (days 3-6), with infection having a negative effect on ADG and ADFI of pigs fed the $\mathrm{L}$ diets but no effect on those offered the $\mathrm{H}$ diets. NSP solubility did not affect ADG, ADFI or feed conversion ratio. There was an effect of NSP inclusion level on ADG over the $14 \mathrm{~d}$ trial period, with pigs on the $\mathrm{H}$ diets gaining less than those on the L diets; 315 (SE 19.8) and 373 (SE 31.5$) \mathrm{g} / \mathrm{d}$, respectively $(P=0 \cdot 050)$. There was no effect of NSP inclusion level on ADFI or feed conversion ratio. There was a significant NSP solubility $\times$ inclusion level interaction on ADG and ADFI over the 3-6d period due to the particularly poor intake and growth of two pigs in the $\mathrm{Hi}-$ treatment group $(\mathrm{H}$, iNSP, sham).

There was an effect of infection $(P=0.004)$ on empty body weight percentage $(\mathrm{EBW} \%)$ on day 6 , with infected pigs having a lower EBW\% than their non-infected counterparts (Table 7). There was no effect of NSP solubility on EBW\% on either day 6 or 14. Pigs on L diets had a higher EBW\% on day 14 than pigs on $\mathrm{H}$ diets ( $\mathrm{L} 87.2$ (SE 0.42) v. H 85.9 (SE 0.43) \%, respectively; $P=0.014$ ). There was no NSP solubility $\times$ NSP inclusion interaction on EBW\%.

Table 7. Effect of non-starch polysaccharide inclusion (high $(\mathrm{H}) v$. low $(\mathrm{L})$ ), solubility (insoluble (i) $v$. soluble (s)) and experimental infection (infected $(+) v$. sham $(-)$ ) on empty body weight (EBW) on days 6 and 14 post-weaning, average daily feed intake (ADFI) and average daily gain (ADG)

(Mean values and standard errors of the difference)

\begin{tabular}{|c|c|c|c|c|c|c|c|c|c|c|}
\hline & \multicolumn{8}{|c|}{ Treatment } & \multirow[b]{2}{*}{ SED† } & \multirow[b]{2}{*}{ Response } \\
\hline & $\mathrm{Hs}-$ & $\mathrm{Hi}-$ & Ls - & $\mathrm{Li}-$ & $\mathrm{Hs}+$ & $\mathrm{Hi}+$ & $\mathrm{Ls}+$ & $\mathrm{Li}+$ & & \\
\hline \multicolumn{11}{|l|}{$A D G(g / d)$} \\
\hline Days 0 to -6 & 101 & 55 & 157 & 109 & 109 & 100 & 50 & 102 & $50 \cdot 4$ & \\
\hline Days 3 to -6 & 292 & 110 & 254 & 266 & 288 & 195 & 150 & 175 & $78 \cdot 8$ & $S \times x l^{*}, I \times x E^{*}$ \\
\hline Days 6 to -14 & 503 & 532 & 676 & 572 & 553 & 521 & 551 & 537 & 82.5 & \\
\hline Days 0 to -14 & 279 & 294 & 465 & 378 & 357 & 331 & 338 & 311 & $65 \cdot 3$ & $I^{*}$ \\
\hline \multicolumn{11}{|l|}{$\operatorname{ADFI}(\mathrm{g} / \mathrm{d})$} \\
\hline Days 0 to -6 & 234 & 198 & 249 & 182 & 209 & 216 & 168 & 187 & 35.9 & $S \times x E^{\star}$ \\
\hline Days 3 to -6 & 320 & 212 & 312 & 258 & 286 & 278 & 204 & 226 & $47 \cdot 0$ & $S \times x l^{*}, I \times x E^{*}$ \\
\hline Days 6 to -14 & 533 & 502 & 688 & 558 & 564 & 505 & 544 & 474 & 79.5 & \\
\hline Days 0 to -14 & 372 & 344 & 513 & 401 & 404 & 365 & 380 & 338 & $65 \cdot 1$ & \\
\hline \multicolumn{11}{|l|}{ EBW (\%) } \\
\hline Day 6 & $89 \cdot 2$ & 89.6 & 86.7 & $90 \cdot 1$ & $89 \cdot 1$ & $87 \cdot 8$ & $87 \cdot 4$ & $87 \cdot 0$ & $1 \cdot 08$ & $E^{\star \star}$ \\
\hline Day 14 & $86 \cdot 2$ & 84.7 & $87 \cdot 2$ & $87 \cdot 2$ & $86 \cdot 8$ & 86.0 & $87 \cdot 8$ & 86.6 & 1.00 & $I^{\star}$ \\
\hline
\end{tabular}

$\mathrm{S}$, solubility (i v. S); I, inclusion level (H v. L); E, experimental infection (infected $v$. non-infected)

${ }^{\star} P<0.05,{ }^{\star \star} P<0.01,{ }^{\star \star \star} P<0.001$.

† Standard error of the difference for the $S \times I \times E$ interaction. 


\section{Discussion}

\section{Experimental infection}

An experimental ETEC challenge was imposed upon half the animals to evaluate the effect of NSP nutrition in a health-challenging environment representative of typical commercial conditions. Infection had little effect on pig health and performance, although there was a significant infection $\times$ NSP inclusion level interaction on performance in the immediate post-infection period (days 3-6), with infection reducing performance to a larger extent in pigs on the $\mathrm{L}$ diets compared with those on the $\mathrm{H}$ diets, perhaps due to the protective effect of elevated dietary NSP levels ${ }^{14,20}$. Although colonies of the ETEC strain to which they were exposed were recovered from the faeces of all inoculated pigs post-infection, only twenty of the thirty-two challenged pigs were still shedding detectable numbers on day 6 (day 3 post-infection). The reason for this apparent lack of persistent ETEC shedding is unclear, although it cannot be excluded that inclusion of inulin and purified cellulose successfully reduced ETEC colonisation. In a previous experiment using the same ETEC strain, level of dose, pig source and infection day, ETEC were recovered from twenty-nine of the thirty-two infected 4-week weaned pigs on day 3 post-infection and there was a significant reduction in ADFI immediately post-infection (days 3-6) in challenged pigs ${ }^{15}$. Subjecting the pigs to further doses of $\mathrm{ETEC}^{5,21}$, may have had resulted in more successful establishment of sub-clinical PWC with a greater impact on the health and performance of the animals.

\section{Non-starch polysaccharide solubility}

Highly fermentable sources of sNSP are thought to undergo virtually complete fermentation in the large intestine unlike iNSP which tend to be less fermentable ${ }^{22}$. If the detrimental effect of sNSP feeding can be attributed to an increase in digesta viscosity, then sNSP sources that do not lead to increased digesta viscosity may be more suitable for weaner diets than iNSP sources due to their greater fermentability. The increased fermentability of sNSP may accelerate physiological and structural development of the $\mathrm{GIT}^{23}$, particularly the proximal large intestine, without compromising pig growth and potentially reduce the incidence and severity of PWC.

The inclusion of inulin, a blend of fructose units connected by $\beta \beta(2-1)$ links $^{24}$, in the diet did not lead to increased digesta viscosity with no significant difference found in either ileal and caecal digesta viscosity of pigs fed sNSP or iNSP diets. These results support the view of Schneeman ${ }^{25}$ who suggests that there is no effect of inulin on the digesta viscosity. A mean ileal digesta viscosity of 1.60 and 1.52 $\log \mathrm{cP}$ for pigs fed the iNSP and sNSP diets respectively was obtained on day 14 , which is comparable with low-viscosity diets used elsewhere ${ }^{9,21}$. Pigs offered the sNSP diets had significantly lower FS and CS than pigs fed the iNSP diets in agreement with the results of Wellock et $a .^{26}$. There was no effect of NSP solubility on faecal ETEC excretion, with infected pigs on both sNSP and iNSP diets shedding similar numbers of ETEC post-infection. This observation contradicts earlier studies suggesting that sNSP facilitate the proliferation of ETEC in the small intestine ${ }^{3,4}$, but supports the view that the observed ETEC proliferation resulted from an increase in digesta viscosity and not sNSP per se.

Differences in dietary carbohydrate composition have been shown to change the gut environment and the composition and density of the gut microflora at different sites along the GIT $^{1,12,13}$. Lactobacilli numbers and the Lactobacillus:coliform ratio in the proximal colon digesta on both days 6 and 14 post-infection were higher in pigs fed the sNSP diets compared with their counterparts on the iNSP diets. As Lactobacilli are considered to promote gut health ${ }^{27,28}$, both by competitive exclusion and the production of lactic acid, which has been shown to have antimicrobial properties ${ }^{29}$, this suggests that sNSP may be more beneficial for gut health than iNSP as was hypothesised.

Pigs fed the sNSP diets had increased levels of VFA in the caecum than those on the iNSP diets as expected. This increased VFA concentration within the caecum reflects the greater fermentability of sNSP and was associated with an increase in caecal development and a significantly lower caecal $\mathrm{pH}$ on day 14 . Increased VFA concentration, particularly butyric acid, has been shown to help maintain the function and health of the GIT and limit the risk of diarrhoea due to the trophic effect on the intestinal epithelium ${ }^{30}$, the stimulation of mucus production, increased $\mathrm{Na}$ and water absorption and decreased digesta $\mathrm{pH}$. Low digesta $\mathrm{pH}$ inhibits the growth of intestinal pathogenic bacteria, such as E. coli and Clostridium difficile ${ }^{31}$, and may help explain the decreased number of coliforms observed in the digesta of pigs fed the sNSP diets, although a reduction in $\mathrm{pH}$ was not consistently observed in the present study.

In vitro and in vivo studies have shown that dietary carbohydrate composition may influence the ratios between the mainly branched-chain VFA (iso-butryic, iso-valeric and valeric acid) and straight-chain VFA (acetic, propionic and butyric acid) ${ }^{32}$. The former are considered to be associated with protein degradation from the metabolism of branched-chain amino acids ${ }^{33}$ while the latter originate mainly from the degradation of carbohydrates ${ }^{18,32}$. As iNSP are less fermentable than sNSP there is less energy available for bacterial fermentation in the large intestine of pigs fed iNSP compared with those fed sNSP. Consequently, it was expected that pigs on the sNSP diets would have a lower BCR than those on the iNSP diets, reflecting a decreased reliance on protein degradation. However, the converse was true with pigs on the sNSP diets having significantly increased BCR in both the proximal colon and caecum on day 14 than pigs on the iNSP diets. The increased amount of valeric acid, particularly on the Hs- treatment ( $\mathrm{H}$, sNSP, sham), was largely responsible for this.

\section{Non-starch polysaccharide inclusion level}

Feeding increased concentrations of iNSP has been shown to be beneficial to pig health. Högberg \& Lindberg ${ }^{14}$ reported that pigs fed a diet high in NSP $(188-250 \mathrm{~g} / \mathrm{kg} \mathrm{DM})$, which consisted of a high proportion of iNSP (0.80-0.85), promoted a beneficial environment throughout the GIT when compared with pigs fed a diet low in NSP (95$109 \mathrm{~g} / \mathrm{kg} \mathrm{DM})$ with a lower proportion of iNSP (0.68-0.73). The beneficial gastrointestinal environment, characterised by 
lower ileal and colonic $\mathrm{pH}$ and increased VFA concentration, was thought to be achieved by promoting the proliferation of lactic acid-producing bacteria, such as Lactobacilli. In the present experiment, NSP concentration had a limited effect on gut health with a significant decrease in the $\mathrm{pH}$ of caecum and proximal colon digesta as NSP inclusion was increased. There was no effect of NSP inclusion on the $\mathrm{Lac}$ tobacillus:coliform ratio in the ileum or proximal colon digesta, although there was a significant decrease in coliform numbers in the proximal colon with an increase in NSP content. Juskiewicz et $a l .{ }^{34}$ reported a similar result in turkeys, whereby an increase in inulin inclusion in the diet from 1 to $10 \mathrm{~g} / \mathrm{kg}$ resulted in a significant decrease in E. coli populations, accompanied by an insignificant but noticeable increase in Bifidobacterium and Lactobacillus counts.

It was hypothesised than increasing the amount of non-viscous NSP in the weaner diet would stimulate a more beneficial gut environment and allow a stable microflora to develop which would help to prevent ETEC colonisation. As a result it was expected that pigs on the $\mathrm{H}$ diets would shed fewer ETEC than those on the L diets. This was observed by Gidenne $\&$ Licois $^{20}$, who reported that experimentally infected rabbits fed a high-NSP diet shed fewer enteropathogenic $E$. coli than those fed a low-NSP diet. Pigs on the $\mathrm{H}$ diets tended to shed $(P=0 \cdot 081)$ fewer ETEC than those on $\mathrm{L}$ diets throughout the post-infection period. The slight increase in digesta viscosity in both the ileum and caecum with an increase in NSP inclusion level may in part have been responsible for the lack of significance, with increased viscosity counteracting the benefit of increased NSP concentration, although the magnitude of increase was considerably lower than in earlier studies where increased digesta viscosity led to increased ETEC proliferation ${ }^{9,21}$.

Increasing NSP inclusion rate enhanced fermentative activity in the large intestine. This was demonstrated by lower digesta $\mathrm{pH}$ values, increased VFA concentration and increased caecum and colon weight of pigs fed $\mathrm{H}$ diets compared with those fed the $\mathrm{L}$ diets. The increase in large-intestinal development of pigs on the $\mathrm{H}$ diets led to a depression in empty-body carcass gain, as observed by McDonald et al. ${ }^{35}$ and Pluske et al. ${ }^{36}$ amongst others. However, the penalty was small and a key question that needs to be addressed is whether there are any long-term effects on carcass yield at slaughter, in terms of both carcass acceptability and profitability. Högberg \& Lindberg $^{13}$ reported that increased NSP concentrations (197 v. $106 \mathrm{~g} \mathrm{NSP/kg} \mathrm{DM)} \mathrm{resulted} \mathrm{in} \mathrm{increased}$ daily gain. However, this was most probably due to the higher energy and protein content of the high-NSP diet compared with the low-NSP diet. Other studies support this view, reporting no adverse effects on ADG and feed conversion ratio of feeding fermentable NSP to young pigs when using isoenergetic and isonitrogenous diets ${ }^{22,37}$. Although the diets in the present trial were formulated to be isoenergetic and isonitrogenous, pigs fed the $\mathrm{H}$ diets gained significantly less than those on the $\mathrm{L}$ diets over the $14 \mathrm{~d}$ trial period. The reason for this observed result is unclear, but may have been due to the unexplained poor growth of two pigs in the Hstreatment group (H, sNSP, sham).

In conclusion, the present results suggest that sNSP per se are not detrimental to weaner pig health. Furthermore, pigs fed the sNSP diets had fewer cases of diarrhoea and improved gut health, as indicated by a lower colonic digesta $\mathrm{pH}$ and increased Lactobacillus:coliform ratio when compared with pigs on the iNSP diets. Increasing the inclusion level of dietary NSP such as inulin that do not lead to increased digesta viscosity may have a beneficial effect on gut health without penalising performance. This in turn will help protect against PWC.

\section{Acknowledgements}

The present research was financially supported by ABNA Ltd, Frank Wright Ltd, Home-Grown Cereals Authority, Meat and Livestock Commission/British Pig Executive, Primary Diets Ltd and Provimi Ltd with match-funding from the Department for Environment, Food and Rural Affairs (Defra), through the Sustainable Livestock Production LINK programme. The authors would like to thank Primary Diets Ltd, UK, for the formulation and manufacture of the experimental diets, Biomathematics and Statistics Scotland for help with the statistical analysis, Dr Frederic Doucet, Dr Gavin White, Eunice Lee and Shulan Feng of the University of Nottingham for viscosity and VFA analysis and Terry McHale, Dave Anderson and Lesley Deans for technical assistance. The research was performed at the Scottish Agricultural College, Edinburgh, UK.

\section{References}

1. Bach Knudsen KE \& Hansen I (1991) Gastrointestinal implications in pigs of wheat and oat fractions 1 . Digestibility and bulking properties of polysaccharides and other major constituents. Br J Nutr 65, 217-232.

2. Bertschinger HU, Eggenberger E, Jucker H \& Pfirter HP (1978) Evaluation of low nutrient, high fibre diets for prevention of porcine Escherichia coli enterotoxaemia. Vet Microbiol 3, $281-290$.

3. Bolduan G, Jung H, Schnable E \& Schneider R (1988) Recent advances in nutrition of weaner piglets. Pig News Inf $\mathbf{9}$, 381-385.

4. McDonald DE, Pethick DW, Pluske JR \& Hampson DJ (1999) Adverse effects of soluble non-starch polysaccharide (guar gum) on piglet growth and experimental colibacillosis immediately after weaning. Res Vet Sci 67, 245-250.

5. Hopwood DE, Pethick DW, Pluske JR \& Hampson DJ (2004) Addition of pearl barley to a rice-based diet for newly weaned piglets increases the viscosity of the intestinal contents, reduces starch digestibility and exacerbates post-weaning colibacillosis. Br J Nutr 92, 419-427.

6. Durmic Z, Pethick DW, Pluske JR \& Hampson DJ (1998) Influence of dietary fibre sources and levels of inclusion on the colonic microflora of pigs, and on the development of swine dysentery in experimentally-infected pigs. J Appl Microbiol 85, 574-582.

7. Hampson DJ, Robertson D, La T, Oxberry SL \& Pethick DW (2000) Influences of diet and vaccination on colonisation of pigs by the intestinal spirochaete Brachyspira (Serpulina) pilosicoli. Vet Microbiol 73, 75-84.

8. Bach Knudsen KE (2001) The nutritional significance of 'dietary fibre' analysis. Anim Feed Sci Technol 90, 3-20.

9. McDonald DE, Pethick DW, Mullan BP \& Hampson DJ (2001) Increasing viscosity of the intestinal contents alters small intestine structure and intestinal growth, and stimulates proliferation of enterotoxigenic Escherichia coli in newly-weaned pigs. $\mathrm{Br} \mathrm{J}$ Nutr 86, 487-498. 
10. Piel C, Montagne L, Seve B \& Lallès JP (2005) Increasing digesta viscosity using carboxymethylcellulose in weaned piglets stimulates ileal goblet cell numbers and maturation. $J$ Nutr 135, 86-91.

11. Lallès JP, Boudry G, Favier C \& Seve B (2006) High-viscosity carboxymethylcellulose reduces carbachol-stimulated intestinal chloride secretion in weaned piglets fed a diet based on skimmed milk powder and maltodextrin. $B r J$ Nutr 95, 488-495.

12. Högberg A \& Lindberg JE (2004) Influence of cereal non-starch polysaccharides on digestion site and gut environment in growing pigs. Livestock Prod Sci 87, 121-130.

13. Högberg A \& Lindberg JE (2004) Influence of cereal non-starch polysaccharides and enzyme supplementation on digestion site and gut environment in weaned pigs. Anim Sci Feed Technol 116, $113-128$.

14. Högberg A \& Lindberg JE (2006) The effect of level and type of cereal non-starch polysaccharide on the performance, nutrient utilization and gut environment on pigs around weaning. Anim Feed Sci Technol 127, 200-219.

15. Wellock IJ, Houdijk JGM \& Kyriazakis I (2007) Effect of weaning age, protein nutrition and enterotoxigenic Escherichia coli challenge on the health of newly weaned piglets. Livestock Sci 108, 102-105.

16. Wellock IJ, Fortomaris PD, Houdijk JGM \& Kyriazakis I (2006) The effect of dietary protein supply on the performance and risk of post-weaning enteric disorders in newly weaned pigs. Anim Sci 82, 327-335.

17. Franklin MA, Mathew AG, Vickers JR \& Clift RA (2002) Characterization of microbial populations and volatile fatty acid concentrations in the jejunum, ileum and cecum of pigs weaned at 17 vs 24 days of age. J Anim Sci 80, 2904-2910.

18. Macfarlane S \& Macfarlane GT (2003) Regulation of shortchain fatty acid production. Proc Nutr Soc 62, 67-72.

19. Lee E, Doucet FJ, Wiseman J \& Hill SE (2006) Newly developed methodologies for the determination of the viscous properties of whole digesta derived from piglets and grown finisher pigs fed soluble or insoluble NSPs-based diets. Newport Sci World 8, 3-4.

20. Gidenne T \& Licois D (2005) Effect of a high fibre intake on the resistance of the growing rabbit to an experimental inoculation with an enteropathogenic strain of Escherichia coli. Anim Sci 80, 287-288.

21. Montagne L, Cavaney FS, Hampson DJ, Lallès JP \& Pluske JR (2004) Effect of diet composition on postweaning colibacillosis in piglets. J Anim Sci 82, 2364-2374.

22. Longland AC, Carruthers J \& Low AG (1994) The ability of piglets 4 to 8 weeks old to digest and perform on diets containing 2 contrasting sources of non starch polysaccharide. Anim Prod 58, $405-410$

23. Aumaître A, Peiniau J \& Madec F (1995) Digestive adaptation after weaning and nutritional consequences in the piglet. Pig News Inf 16, 73N-79N.
24. Roberfroid MB (2005) Introducing inulin-type fructans. $\mathrm{Br} J$ Nutr 93, S13-S25.

25. Schneeman BO (1999) Fiber, inulin and oligofructose: similarities and differences. J Nutr 129, 1424S-1427S.

26. Wellock IJ, Houdijk JGM \& Kyriazakis I (2007) Effect of dietary non-starch polysaccharide solubility and inclusion level on gut health and the risk of post weaning enteric disorders in newly weaned piglets. Livestock Sci 108, 186-189.

27. Hampson DJ, Pluske JR \& Pethick DW (2001) Dietary manipulation of enteric disease. In Digestive Physiology of Pigs, pp. 247-258 [JE Lindberg and B Ogle, editors]. Wallingford, UK: CABI Publishing.

28. Pluske JR, Kim JC, McDonald DE, Pethick DW \& Hampson DJ (2001) Non-starch polysaccharides in the diets of young weaned piglets. In The Weaner Pig: Nutrition and Management, pp. 81-112 [MA Varley and J Wiseman, editors]. Wallingford, UK: CABI Publishing.

29. Nout MJ, Rombouts FM \& Havelaar A (1989) Effect of accelerated neutral lactic acid fermentation on infant food ingredients on some pathogenic microorganisms. Int J Food Mircrobiol 8, $351-361$.

30. Williams BA, Verstegen MWA \& Tamminga S (2001) Fermentation in the large intestine of single-stomached animals and its relationship to animal health. Nutr Res Rev 14, 207-227.

31. Prohászka L (1986) Antibacterial mechanism of volatile fatty acids in the intestinal tract of pigs against Escherichia coli. Zentralbl Veterinarmed B 33, 166-173.

32. Bach Knudsen KE, Jensen BB \& Hansen L (1993) Digestion of polysaccharides and other major components in the small and large intestine of pigs. Br J Nutr 70, 537-556.

33. Macfarlane GT, Gibson GR, Beatty E \& Cummings JH (1992) Estimation of short-chain fatty acid production from protein by human intestinal bacteria based on branch-chained fatty acid measurements. FEMS Microbiol Ecol 101, 81-88.

34. Juskiewicz J, Jankowski J, Zdunczyk Z, Biedrzycka E \& Koncicki A (2005) Performance and microbial status of turkeys fed diets containing different levels of inulin. Arch Geflugelkunde 69, 175-180.

35. McDonald DE, Pluske JR, van Barneveld RJ, Pethick DW, Mullan BP \& Hampson DJ (1998) The effects of non-starch polysaccharides and resistant starch on weaner pig performance and digestive tract development. Proc Nutr Soc Aust 22, 1000 .

36. Pluske JR, Black B, Pethick DW, Mullan BP \& Hampson DJ (2003) Effects of different sources and levels of dietary fibre in diets on performance, digesta characteristics and antibiotic treatment of pigs after weaning. Anim Feed Sci Technol 107, 129-142.

37. Gill BP, Mellange J \& Rooke JA (2000) Growth performance and apparent nutrient digestibility in weaned piglets offered wheat, barley or sugar beet pulp based diets supplemented with food enzymes. Anim Sci 70, 107-118. 